\title{
Influência da variação sazonal nos teores de flavonóides e atividade antioxidante das folhas de Campomanesia adamantium (Cambess.) O. Berg, Myrtaceae
}

\author{
Isabel D. Coutinho, ${ }^{1}$ Vanessa M. F. Kataoka, ${ }^{1}$ Neli K. Honda, ${ }^{2}$ Roberta G. Coelho, ${ }^{2}$ \\ Maria C. Vieira, ${ }^{3}$ Claudia A. L. Cardoso ${ }^{*}, 1,2$ \\ ${ }^{1}$ Curso de Química, Universidade Estadual de Mato Grosso do Sul, Rodovia Dourados-Itahum km 12, \\ Cidade Universitária, Caixa Postal 351, 79804-970 Dourados-MS, Brasil, \\ ${ }^{2}$ Departamento de Química, Universidade Federal de Mato Grosso do Sul, Caixa Postal 649, 79070-900 \\ Campo Grande-MS, Brasil, \\ ${ }^{3}$ Departamento de Agronomia, Universidade Federal da Grande Dourados, Caixa Postal 651, 79804-970 \\ Dourados-MS, ,Brasil.
}

\begin{abstract}
RESUMO: Campomanesia adamantium (Cambess.) O. Berg, Myrtaceae, é uma espécie nativa. As folhas são utilizadas na medicina popular. Os extratos hexânico e acetato de etila das folhas mostraram pouca variação na sua composição química em diferentes estações do ano associado com o desenvolvimento do vegetal, enquanto o extrato etanólico mostrou alteração significativa em relação à composição química. Todos os extratos etanólicos mostraram alta atividade antioxidante frente ao método DPPH e de moderada a alta para $\beta$-caroteno/ácido linoléico.
\end{abstract}

Unitermos: Campomanesia adamantium, guavira, guabiroba, sazonal

\begin{abstract}
The Influence of seasonal variation in levels of flavonoids and antioxidant activity of the leaves of Campomanesia adamantium". Campomanesia adamantium (Cambess.) O. Berg, Myrtaceae, is a native species. The extracts of ethyl acetate and hexane showed little variation in their chemical composition at different seasons of the year associated with the development of the plant, while the ethanol extract showed significant change in relationship to chemical composition. All ethanol extracts showed high antioxidant activity against DPPH method and from moderate to high antioxidant activity for $\beta$-carotene/linoleic acid.
\end{abstract}

Keywords: Campomanesia adamantium, guavira, guabiroba, seasonal

\section{INTRODUÇÃO}

O cerrado brasileiro é tido como fonte de recursos biológicos e potencialmente econômico e possui um grande número de espécies frutíferas, ornamentais e medicinais. As comunidades do Cerrado são consideradas complexas e as variações climáticas, caracterizadas pela distinção entre uma estação chuvosa (outubro a março) e outra seca (abril a setembro) representam a principal limitação do Cerrado, influenciando as estruturas das diversas espécies vegetais presentes (Pott \& Pott, 1996).

A espécie Campomanesia adamantium (Cambess.) O. Berg ocorre em fisionomias campestres de cerrado e em cerrado típico, sendo encontrada na região do Estado de São Paulo e Mato Grosso do Sul. É conhecida popularmente pelos nomes de guavira e guabiroba. As folhas são utilizadas na medicina popular para desarranjos estomacais e infecções do trato urinário (Piva, 2002).

Apesar de sua importância econômica e cultural, poucos são os estudos químicos encontrados com a espécie C. adamantium. Análise dos óleos essenciais das folhas, frutos e flores apresentou baixo rendimento com a presença de mono e sesquiterpenos (Vallilo et al., 2004; Vallilo et al., 2006a,b; Coutinho et al., 2008). Coutinho (2008) estudou as folhas de $C$. adamantium, que mostraram-se ricas em flavanonas e chalconas. A literatura relata a correlação entre o consumo de frutas e vegetais e a redução do risco de doenças crônicas com relação aos compostos fenólicos (Wu et al., 2004; Vasco et al., 2008).

Este trabalho teve como objetivo a análise das folhas de C. adamantium visando uma comparação dos constituintes presentes nas folhas coletadas em diferentes épocas do ano e sua atividade antioxidante. 


\section{MATERIAIS E MÉTODOS}

\section{Coleta e identificação do material}

As folhas de C. adamantium (Cambess.) O. Berg, Myrtaceae, foram coletadas no município de Bela-Vista, MS, a 180 metros de altitude segundo as coordenadas geográficas latitude $22^{\circ} 06^{\prime} \mathrm{S}$ e longitude $056^{\circ} 33^{\prime} \mathrm{W}$, em diferentes estações do ano de 2007: verão $(\mathrm{CaV})$ (quente e úmido), outono (CaO) (frio e seco) e primavera (Caip) (clima quente e seco). Nas estações verão e outono a planta encontra-se no estágio vegetativo, enquanto na primavera a planta encontra-se no estágio reprodutivo (Pott \& Pott, 1996). A espécie foi identificada por Marcos Sobral da UFMG e depositada no Herbário Mato Grosso do SulHMS, Campo Grande, Brasil.

\section{Preparação dos extratos}

Os extratos foram preparados a partir de $20 \mathrm{~g}$ de folhas trituradas em triturador de aço e submetidos à maceração com $200 \mathrm{~mL}$ dos solventes $n$-hexano, acetato de etila, etanol e metanol, seqüencialmente, em ordem crescente de polaridade, onde cada solvente permaneceu em contato com as folhas durante $48 \mathrm{~h}$. Estas condições de extração foram previamente otimizadas pela análise por CLAE de dez amostras preparadas nas mesmas condições, as quais foram monitoradas em relação aos constituintes em análise a cada $12 \mathrm{~h}$ por um período de $96 \mathrm{~h}$.

Foram obtidos os extratos hexânicos (Hex): CavHex (extrato hexânico das folhas de Campomanesia adamantium coletadas durante o verão), CaoHex (extrato hexânico das folhas de Campomanesia adamantium coletadas durante o outono) e CaipHex (extrato hexânico das folhas de Campomanesia adamantium coletadas durante a primavera), acetato de etila (AcOEt): CavAcOEt (extrato acetato de etila das folhas de Campomanesia adamantium coletadas durante o verão), CaoAcOEt (extrato acetato de etila das folhas de Campomanesia adamantium coletadas durante o outono) e CaipAcOEt (extrato acetato de etila das folhas de Campomanesia adamantium coletadas durante a primavera), etanólico (EtOH): CavEtOH (extrato etanólico das folhas de Campomanesia adamantium coletadas durante o verão), $\mathrm{CaoEtOH}$ (extrato etanólico das folhas de Campomanesia adamantium coletadas durante o outono), e CaipEtOH (extrato etanólico das folhas de Campomanesia adamantium coletadas durante a primavera), de diferentes épocas do ano.

Durante o processo de solubilização dos extratos em metanol para obtenção das soluções estoque, verificouse que os extratos hexânicos obtidos em diferentes épocas do ano não dissolveram completamente. Nestes foram adicionadas porções de acetona e mantidos a temperatura de $4{ }^{\circ} \mathrm{C}$ e com isso houve a precipitação de substâncias insolúveis, como hidrocarbonetos de cadeia longa. Os precipitados obtidos foram separados dos sobrenadantes.
Os sobrenadantes foram secos e dissolvidos em metanol para obtenção das soluções estoques dos extratos hexânicos.

\section{Análises por Cromatografia Líquida de Alta Eficiência com detector de arranjo de diodos (CLAE-DAD)}

Todas as amostras obtidas foram analisadas empregando-se um Cromatógrafo Líquido de Alta Eficiência, modelo: Varian 210, detector de arranjo de diodos (DAD), com varredura entre $200-800 \mathrm{~nm}$. A coluna utilizada para as análises foi de fase reversa C-18 $(25 \mathrm{~cm} \mathrm{x}$ $4,6 \mathrm{~mm} \times 5 \mu \mathrm{m})$ e pré-coluna $(2,5 \mathrm{~cm} \times 3 \mathrm{~mm})$ de mesma fase da coluna (Phenomenex). A eluição foi realizada com solventes de grau CLAE em sistema gradiente, nas seguintes condições cromatográficas: Iniciou-se com $40 \%$ de metanol, $50 \%$ de água e $10 \%$ de acetonitrila indo até 40 min até atingir $80 \%$ de metanol, $10 \%$ de água e $10 \%$ de acetoniltrila e 20 min para voltar à condição inicial. Tempo de análise foi de $60 \mathrm{~min}$. Vazão de fluxo da bomba de $1 \mathrm{~mL}$ min-1.

As substâncias presentes nos extratos foram previamente isoladas de C. adamantium (Coutinho, 2008). Essas substâncias foram repurificadas por CLAE analítico, através de cinco injeções de $0,1 \mathrm{~mL}$ partindo de uma solução estoque de $7 \mathrm{mg} \mathrm{mL}^{-1}$ obtendo-se pureza entre $90-94 \%\left[3,5,7,3^{\prime}, 4^{\prime}, 5^{\prime}\right.$ '-pentaidroxiflavonolO-3- $\alpha$-L-raminopiranosídeo (1) $\quad(90 \%, \quad 0,3 \quad \mathrm{mg})$, 7-hidróxi-6-metil-5-metóxiflavanona (2) $(92 \%, 0,7 \mathrm{mg})$, 5,7-diidróxi-6-metilflavanona (3) $(93 \%, 0,7 \mathrm{mg}), 5,7-$ diidróxi-8-metilflavanona (4) $(91 \%, 0,6 \mathrm{mg}), 2$ ', 4'diidroxi-6'-metóxichalcona (5) $(92 \%, 0,7 \mathrm{mg}), \quad 5,7-$ diidróxi-6,8-dimetilflavanona (6) $\quad(92 \%, \quad 0,8 \quad \mathrm{mg})$, 2',4'-diidróxi-3',5'-dimetil-6'-metóxichalcona (7) $(92 \%$, $0,7 \mathrm{mg})]$.

As substâncias foram dissolvidas, separadamente, em metanol grau cromatográfico para preparação das soluções estoques e filtradas com ultrafiltro de $0,22 \mu \mathrm{m}$. Foram realizadas injeções de volumes variados da solução estoque de cada analito $(2,5,10,15$ e $20 \mu \mathrm{L})$. Para cada analito foi obtido um cromatograma, deste foi retirada a área onde foi construída a curva analítica de área versus massa de cada substância. Através da análise de regressão linear foi possível estabelecer o coeficiente de correlação, bem como os coeficientes angular e linear para determinação da concentração destas substâncias nos extratos avaliados.

\section{Ensaios de atividade antioxidante}

O ensaio de atividade antioxidante empregando o sistema $\beta$-caroteno/ácido linoléico foi realizado como descrito por Tepe et al. (2005) com algumas modificações e foi realizado nas seguintes amostras de todos os extratos obtidos da coleta sazonal. Uma solução estoque de $\beta$-caroteno e ácido linoléico foi preparada a partir de 0,5 mg de $\beta$-caroteno dissolvido em $1 \mathrm{~mL}$ de clorofórmio e adicionado a $25 \mu \mathrm{L}$ de ácido linoléico e $200 \mathrm{mg}$ de Tween 
20. O clorofórmio foi removido sobre nitrogênio líquido. A mistura resultante teve seu volume completado para 100 $\mathrm{mL}$ de água milli-Q aerada. O teste foi realizado através da adição de $2,5 \mathrm{~mL}$ da mistura e $0,3 \mathrm{~mL}$ de amostra nas concentrações de 10-160 $\mu \mathrm{g} \mathrm{mL}^{-1}$ e imediatamente a leitura foi realizada no tempo zero a $470 \mathrm{~nm}$ e $2 \mathrm{~h}$ depois dos tubos permancerem incubados a $50{ }^{\circ} \mathrm{C} \mathrm{em}$ banho-maria. $\mathrm{O}$ controle foi preparado substituindo a amostra pelo mesmo volume de metanol. Todos os ensaios foram realizados em triplicata. Como padrão foi utilizado BHT na concentração de $10-160 \mu \mathrm{g} \mathrm{mL}^{-1}$. da equação:

A inibição da peroxidação foi calculada a partir

Inibição da peroxidação lipídica $(\%)=($ conteúdo de $\beta$-caroteno depois de $2 \mathrm{~h}$ do ensaio/conteúdo inicial de $\beta$-caroteno) x 100 .

A determinação da atividade antioxidante empregando o radical livre 2,2-difenil-1-picril-hidrazila (DPPH) a $0,004 \%$, foi baseada na habilidade de compostos fenólicos em doar um próton para o DPPH e formar estruturas de ressonância estáveis, estabilizando assim o radical livre. Este ensaio foi realizado de acordo com o método descrito por Blois (1958), nas amostras de todos os extratos obtidos da coleta sazonal, onde alíquotas de $1 \mathrm{~mL}$ de cada amostra nas concentrações de $10-160 \mu \mathrm{g} \mathrm{mL}^{-1}$ foram adicionadas a $2 \mathrm{~mL}$ da solução de DPPH e incubada na temperatura ambiente por 30 min. A leitura da absorvância de cada amostra foi realizada em espectrofotômetro a $517 \mathrm{~nm}$. O controle foi preparado substituindo a amostra pelo mesmo volume de metanol. Todos os ensaios foram realizados em triplicata. Como padrão foi utilizado a quercetina na concentração de $10-160 \mu \mathrm{g} \mathrm{mL}^{-1}$.

O efeito "sequestro" de radical (\%) foi calculado usando a seguinte equação:

Efeito "seqüestro" de radical $(\%)=(\mathrm{A} 0-\mathrm{A}) \times 100 / \mathrm{A} 0$

onde $A_{0}$ é a absorvância do DPPH (controle) e A é a absorbância da amostra mais DPPH. Nos dois testes de atividade antioxidante foram calculados os valores da $\mathrm{CI}_{50}$.

\section{RESULTADOS E DISCUSSÃO}

As Figuras 1-3 mostram os perfis cromatográficos dos extratos hexânicos (CavHex, CaoHex e CaipHex), acetato de etila (CavAcOEt, CaoAcOEt e CaipAcOEt) e etanólico (CavEtOH, CaoEtOH e CaipEtOH), respectivamente, em $284 \mathrm{~nm}$. Este comprimento de onda foi escolhido, tendo em vista que é o mais representativo da amostra, pois foi possível detectar todos os picos presentes do início ao fim do cromatograma. Primeiramente foram avaliados e comparados qualitativamente os perfis cromatográficos de cada extrato de mesma polaridade, mas em amostras coletadas em épocas diferentes, foram realizadas as quantificações das substâncias nessas mesmas amostras.

Em relação às amostras obtidas dos extratos acetato de etila, foi possível observar que as amostras CavAcOEt, CaoAcOEt e CaipAcOEt são semelhantes (Figura 2), com exceção da ausência do pico 1 referente a 3,5,7,3',4',5'pentaidroxiflavonol- $O-3-\alpha-L-$-raminopiranosídeo (1) no extrato CaipAcOEt.

As amostras CavHex, CaoHex e CaipHex mostraram perfis cromatográficos semelhantes em relação à presença das substâncias 2-7 (Figura 1). Estas mesmas substâncias foram detectadas nos extratos obtidos com o solvente acetato de etila (Figura 2). Como o acetato de etila é mais polar do que o hexano apresentou mais picos no início do cromatograma, indicando a presença de substâncias com características mais polares como a presença do pico 1 referente a $3,5,7,3^{\prime}, 4^{\prime}, 5^{\prime}$-pentaidroxiflavonol- $O-3-\alpha$ L-raminopiranosídeo no extrato CavAcOEt e CaoAcOEt (Figura 2).

Foi observado diferenças nos perfis cromatográficos dos extratos CavEtOH, CaoEtOH e CaipEtOH das folhas de C. adamantium coletadas em diferentes estações do ano. Na amostra CavEtOH, foi possível observar maior quantidade de picos do que nas amostras referentes ao outono e primavera (Figura 3).

Com base nestes dados foi possível observar que as amostras que se referem aos extratos hexânico e acetato de etila mostraram pouca variação na sua composição química em diferentes estações do ano associado com o desenvolvimento do vegetal, enquanto o extrato etanólico mostrou alteração significativa em relação à composição química, indicando que as substâncias que compõem os mesmos são alteradas de acordo com a variação sazonal e desenvolvimento do vegetal.

As curvas analíticas das substancias quantificadas foram preparadas pelo método de padrão externo e apresentaram $r \geq 0,998$ indicando um bom coeficiente de correlação entre as concentrações analisadas. A Figura 4 mostra os teores totais dessas substâncias nas amostras coletadas no verão, primavera e outono, independente do teor obtido em cada extrato.

A substância 7 mostrou maior teor em todas as amostras. A coleta da primavera mostrou maior teor de flavanonas $(2,3,4$ e 6) e chalconas $(5,7)$.

A Figura 5 mostra o efeito "seqüestro" de radical nas amostras coletadas em diferentes estações do ano. As amostras CavHex e CaoHex mostraram baixa atividade antioxidante com percentual médio de $38,30 \%$ com diminuição para $19,15 \%$ da amostra CaipHex, enquanto as amostras CavAcOEt, CaoAcOEt e CaipAcOEt apresentaram alta atividade antioxidante com valores de atividades de $90,74 \%$ e $92,07 \%$ para as amostras CavAcOEt e CaoAcOEt, respectivamente, e com redução para 61,57 $\%$ para a amostra CaipAcOEt. Esta diferença na atividade entre os extratos AcOEt pode ser atribuída a presença de 
1 e de outros flavonóides no início do cromatograma no tempo de retenção de 2-10 min das amostras CavAcOEt e CaoAcOEt, e ausência destas em CaipAcOEt.

Nos resultados obtidos através do ensaio da inibição da peroxidação lipídica (Figura 5) mostram que a amostra CaipHex apresentou maior atividade antioxidante $(71,65 \%)$ a $160 \mu \mathrm{g} \mathrm{mL}^{-1}$ do que CavHex $(34,64 \%)$ e CaoHex $(43,27 \%)$ na mesma concentração, embora esses últimos mostraram maior atividade antioxidante no método $\beta$-caroteno/ácido linoléico do que o método do DPPH. A amostra CaoAcOEt mostrou maior percentual de atividade antioxidante $(88,61 \%)$, seguida da amostra CavAcOEt (64,72\%) e CaipAcOEt (53,23\%). Assim, como observado para o método do DPPH, esta diferença na atividade pode ser atribuída a presença de $\mathbf{1}$ nas amostras CaoAcOEt e CavAcOEt, pois estudo da inibição da peroxidação lipídica de 1 mostrou que esta substância é um agente antioxidante com $\mathrm{CI}_{50}$ de $220 \mu \mathrm{g} \mathrm{mL}^{-1}$ (Hayder et al., 2008). As amostras $\mathrm{CaoEtOH}(79,69 \%)$ e CavEtOH $(53,73 \%)$ mostraram menores valores de atividade antioxidante do que as amostras do extrato acetato de etila.

Em relação aos extratos hexânicos a amostra CaipHex mostrou maior atividade antioxidante frente ao método $\beta$-caroteno/ácido linoléico do que as amostras CavHex e CaoHex, porém o oposto foi observado para o método do DPPH, no qual a atividade antioxidante diminuiu (CaipHex $<$ CavHex $<$ CaoHex).

Os dois ensaios de atividade antioxidante mostraram moderada correlação entre eles, onde o ensaio do DPPH apresentou maior percentual de inibição do que o ensaio da inibição da peroxidação lipídica, sendo

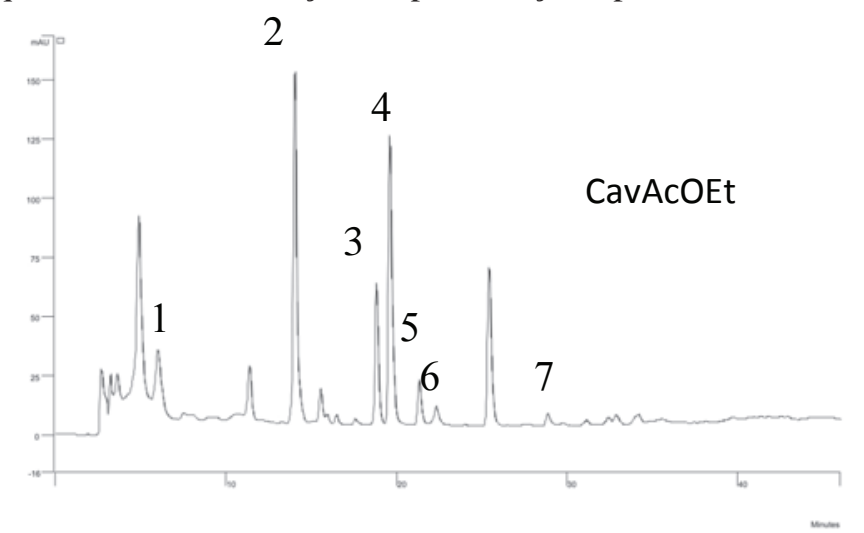

o primeiro afetado pela composição da doação de átomos de hidrogênio (DPPH) e o segundo pelo "seqüestro" de oxigênio (peroxidação do ácido linoléico) (Sultana et al., 2007).

O aumento no teor de chalconas pode estar associado a estratégia biossíntética para formação de flavanonas (Dewick, 2005; Scröder et al., 1998) durante o período da primavera. Assim como, estudos mostraram que a alteração de fotoperíodos durante as diferentes estações do ano pode interferir na produção dos metabólitos secundários dos vegetais como uma estratégia de defesa da planta (Harbone, 1994), principalmente os compostos fenólicos que são agentes de defesa contra vários tipos de estresse causados por patógenos ou condições ambientais adversas (Treutter, 2001).

Através do monitoramento da variação da composição química associada a fatores ambientais e fenológicos na espécie $C$. adamantium no presente estudo pode-se inferir que o aumento da disponibilidade hídrica na fenofase pós-frutificação aumentou o teor de flavonóide glicosado e diminuiu o teor de flavonóides agliconas. Conseqüentemente após o período de estiagem e geada, durante o inverno, a planta entrou em senescência, fenômeno observado através da perda das folhas, após este período no início da primavera foi possível verificar a formação de folhas e aumento da temperatura, onde foi possível observar através das análises de CLAE (Figura 4) um aumento no teor de flavanonas e chalconas. Este aumento pode estar relacionado ao acúmulo de flavonóides na superfície da folha como proteção aos raios UV e/ ou mesmo como defesa a insetos, tais como os estudos de

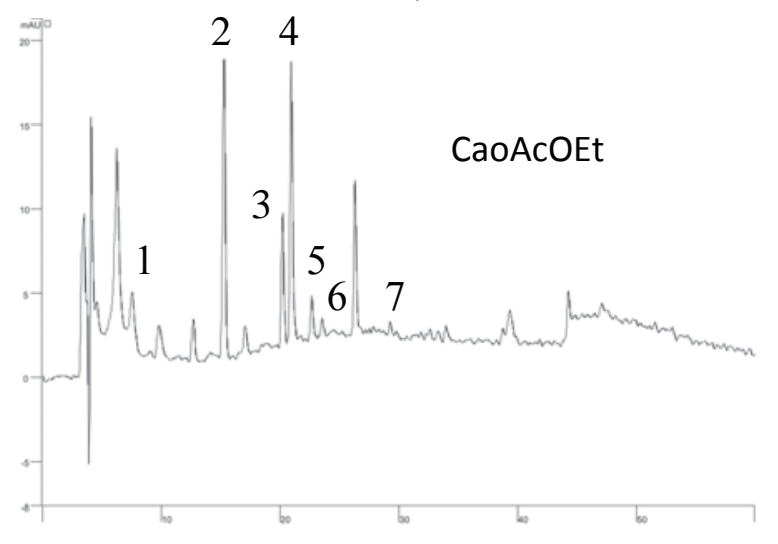

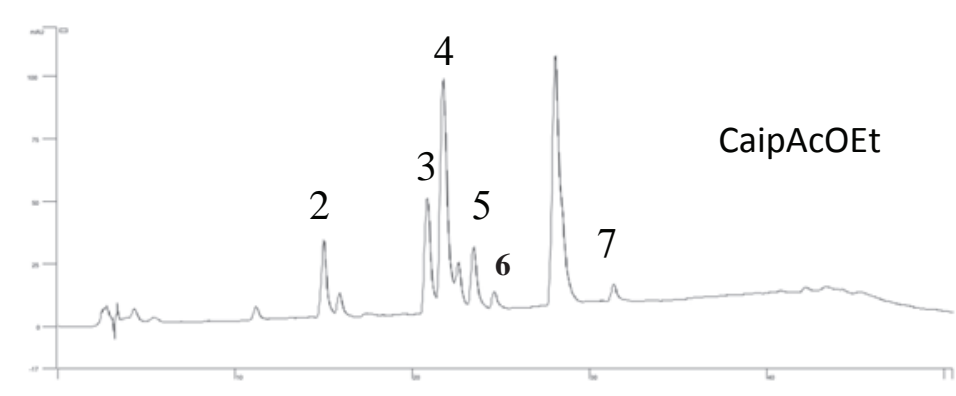

Figura 1. Perfil cromatográfico representativo dos extratos acetato de etila das folhas de Campomanesia adamantium coletadas durante o verão (CavAcOEt), coletadas durante o outono (CaoAcOEt) e coletadas durante a primavera (CaipAcOEt) $(\lambda=284 \mathrm{~nm})$. 

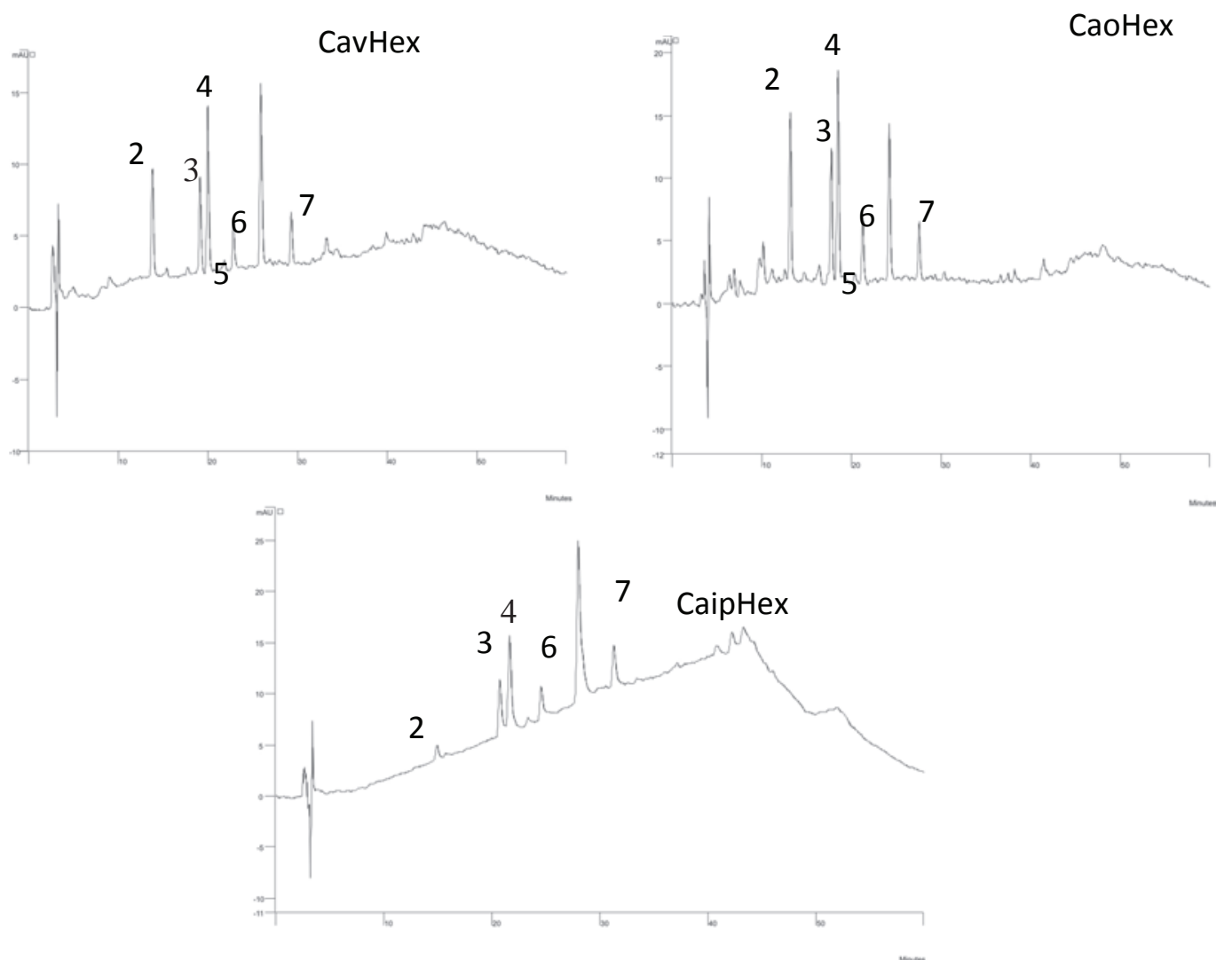

Figura 2. Perfil cromatográfico representativo dos extratos hexânicos das folhas de Campomanesia adamantium coletadas durante o verão (CavHex), coletadas durante o outono (CaoHex) e coletadas durante a primavera $(\mathrm{CaipHex})(\lambda=284 \mathrm{~nm})$.
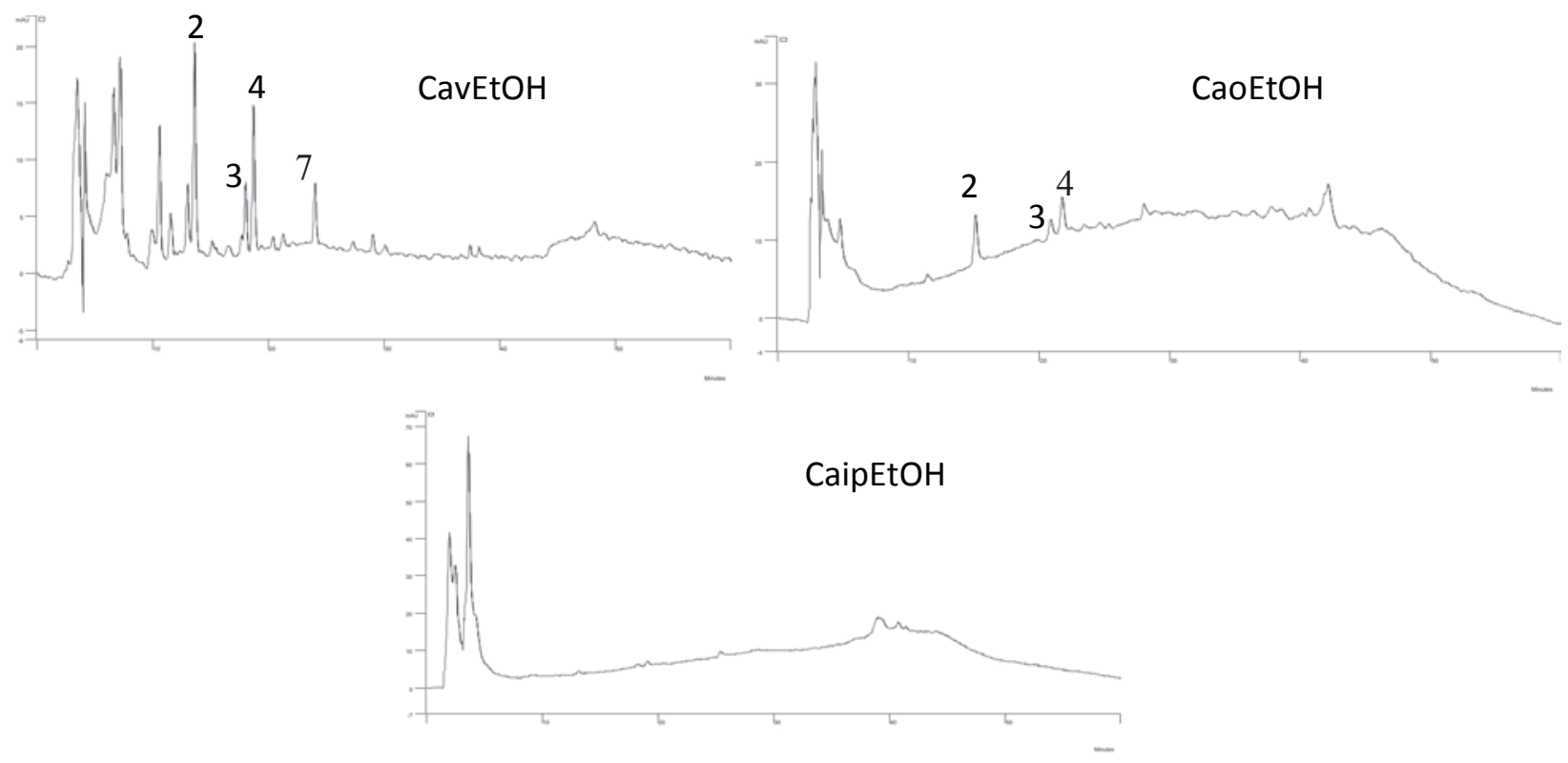

Figura 3. Perfil cromatográfico representativo dos extratos etanólicos das folhas de Campomanesia adamantium coletadas durante o verão $(\mathrm{CavEtOH})$, coletadas durante o outono $(\mathrm{CaoEtOH})$ e coletadas durante a primavera $(\mathrm{CaipEtOH})(\lambda=284 \mathrm{~nm})$. 


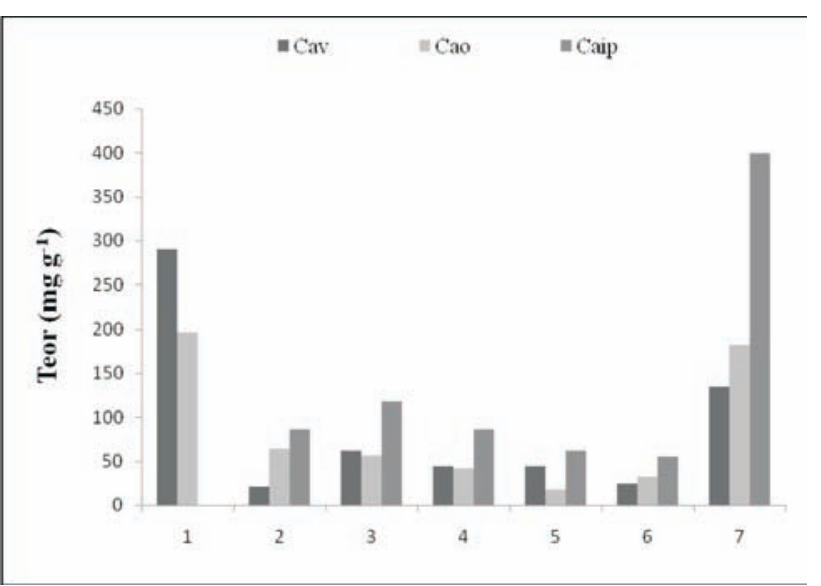

Figura 4. Teores (mg g-1) das substâncias monitoradas em diferentes estações em Campomanesia adamantium.

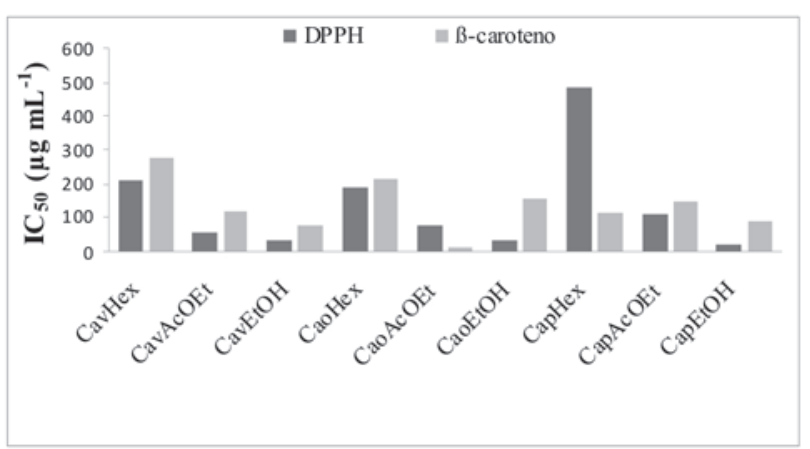

Figura 5. Concentração inibitória $\left(\mathrm{CI}_{50}\right)$ das amostras no método efeito "sequestro" de radical e inibição da peroxidação lipídica.

Mimulus aurantiacus (Simmonds, 2003).

A partir dos resultados obtidos pode se concluir que a alteração na composição química das folhas de $C$. adamantium em diferentes estações do ano pode estar influenciando no aumento ou descréscimo da atividade antioxidante.

\section{AGRADECIMENTOS}

À Fundação de Apoio ao Desenvolvimento do Ensino, Ciência e Tecnologia do Estado do Mato Grosso do Sul (Fundect) pelo apoio financeiro concedido a pesquisa, UEMS e CNPq.

\section{REFERÊNCIAS}

Blois MS 1958. Antioxidant determinations by the use of a stable free radical. Nature 181: 1199-1200.

Coutinho ID, Poppi NR, Cardoso CL 2008. Identification of the volatile compounds of leaves and flowers in Guavira (Campomanesia adamantium O. Berg). J Essen Oil Res 20: 405-407.

Coutinho ID 2008. Estudo químico e atividades biológicas de Campomanesia adamantium (Cambess.) O. Berg (Myrtaceae). Campo Grande, 159p. Dissertação de Mestrado, Programa de Pós-graduação em Química,
Universidade Federal de Mato Grosso do Sul.

Dewick PM 2005. Medicinal Natural Products: a Biosynthetic Approach. England: John Wiley \& Sons, LTD.

Hayder N, Bouhle I, Skandrani I, Kadri M, Steiman R, Guiraud P, Mariotte A-M, Ghedira K, Dijoux-Franca M-G, ChekirGhedira L 2008. In vitro antioxidant and antigenotoxic potentials of myricetin-3-O-galactoside and myricetin3-O-rhamnoside from Myrtus communis: modulation of expression of genes involved in cell defence system using cDNA microarray. Toxicol in vitro 22: 567-581.

Harbone JB, 1994. The flavonoids-advances in research since 1986. London: Chapman \& Hall.

Piva MG 2002. O Caminho das Plantas Medicinais: Estudo Etnobotânico. Rio de Janeiro: Mondrian.

Pott A, Pott VJ 1996. Flora do Pantanal: listagem atual de fanerógamas. II Simpósio sobre recursos naturais $e$ sócio-econômico do Pantanal: Manejo e Conservação. Corumbá, Brasil.

Schröder J, Raiber S, Berger T, Schmidt A, Schmidt J, Soaressello AM, Bardshiri E, Strack D, Simpson TJ, Veit M, Schröder G 1998. Plant polyketide synthases: a chalcone synthase-type enzyme which performs a condensation reaction with methylmalonyl-CoA in the biosynthesis of c-methylated chalcones. Biochemistry-US 37: 84178425 .

Simmonds MSJ 2003. Flavonoid-insect interactions: recent advances in our knowledge. Phytochemistry 64: 21-30.

Sultana B, Anwar F, Przybylski R 2007. Antioxidant activity of phenolic components present in barks of Azadirachta indica, Terminalia arjuna, Acacia nilotica, and Eugenia jambolana Lam. Trees. Food Chem 104: 1106-1114.

Tepe B, Daferera D, Sokmen A, Sokmen B, Polissiou M 2005. Antimicrobial and antioxidante activity of the essential oil and various extracts of Cyclotrichium origanifolium (Labill.) Manden. \& Scheng. J Food Eng 69: 335-342.

Treutter D, 2001. Biosynthesis of phenolic compounds and its regulation in apple. Plant Growth Regul 34: 71-89.

Vallilo MI, Aguiar OT, Fiumarelli J, Martins Junior HA, Sassine A, Bustillos OV 2004. Identificação de terpenos no óleo dos frutos de Campomanesia adamantium (Cambessédes) $\mathrm{O}$. Berg. Landrum- Myrtaceae. Arq Inst Biol 71: 115-116.

Vallilo MI, Bustillos OV, Aguiar OT 2006a. Identificação de terpenos no óleo essencial dos frutos de Campomanesia adamantium (Cambessédes) O. Berg- Myrtaceae. Rev Inst Flor 18: 15-22.

Vallilo MI, Lamardo LCA, Gaberlotti ML, Oliveira E, Moreno PRH 2006b. Composição química dos frutos de Campomanesia adamantium (Cambessédes) O. Berg. Cien Tecnol Aliment 26: 805-810.

Vasco C, Ruales J, Kamal-Eldin A 2008. Total phenolic compounds and antioxidant capacities of major fruits from Ecuador. Food Chem 111: 816-823.

Wu X, Beecher GR, Holden JM, Haytowitz DB, Gebhardt SE, Prior RL 2004. Lipophilic and hydrophilic antioxidant capacities of common foods in the United States. J Agri Food Chem 52: 4026-4037. 